\title{
FLUORIDE RELEASING POTENTIAL AND RECHARGING CAPACITY OF DIFFERENT BIOACTIVE RESTORATIVE MATERIALS (A COMPARATIVE IN-VITRO STUDY)
}

\author{
Eman Mohamed Sobhy Elbahrawy* and Reham Mohamed Attia**
}

\begin{abstract}
Statement of The Problem: Since the fluoride releases from materials with the property of releasing fluoride is decreasing gradually, it seems that probably the material rechargeability is more important than its long-term fluoride release.

Objective: This study aimed to asses and compare the fluoride releasing potential and recharging capacity of different bioactive restorative materials in-vitro.

Materials and Methods: The sample consisted of 50 freshly extracted premolar teeth. Standardized buccal class V cavities were prepared. Samples were randomly divided into 5 main groups ( $\mathrm{n}=10$ /group), representing materials used; Conventional glass ionomer cement (CGIC) ; G C Fuji IX G P, resin modified glass ionomer restoration (RMGI); Fuji II LC, Compomer; Dyract XP, Giomer; Beautiful II and one enhanced RMGI; ACTIVA Bioactive-Restorative. Each material was evaluated for its fluoride releasing potential and recharging capacity after topical application of fluoride varnish at $1^{\text {st }}, 3^{\text {th }}, 7^{\text {th }}, 14^{\text {th }}, 21^{\text {th }}$ and $28^{\text {th }}$ days.
\end{abstract}

Results: There was a statistically significant difference between each tested materials at all time intervals before and after recharging with topical fluoride varnish where $(\mathrm{p} \leq 0.001)$. The highest mean value of fluoride releasing potential and recharging capacity was in (Day-1), and the least mean value was in (Day-28). There was a statistically significant difference between the tested materials at each time interval regarding fluoride release before and after recharge.; CGIC (GC Fuji IX GP) showed the highest mean values of fluoride releasing potential and recharging capacity at each time interval $\left(1^{\text {st }}, 3^{\text {th }}, 7^{\text {th }}, 14^{\text {th }}, 21\right.$ th and 28 th days $)$, while the lowest mean values were observed in compomer (Dyract XP) at each time interval $\left(1^{\text {st }}, 3^{\text {th }}, 7^{\text {th }}, 14^{\text {th }}, 21^{\text {th }}\right.$ and 28 th days $)$.

Conclusion: The CGIC was considered to be the material with the highest fluoride releasing potential and recharging capacity, while compomer showed the lowest fluoride releasing potential and recharging capacity at each time interval. It was observed that the enhanced RMGI (ACTIVIA Bioactive-Restorative) showed a lower fluoride releasing potential and fluoride recharging capacity than those of CGIC (GC Fuji IX GP), higher values than those of both Compomers and RMGI and comparable to those of Giomer at each time interval.

KEY WORDS: CGIC'S, RMGI, Compomer, Giomer, ACTIVA Bioactive-Restorative, Fluoride Releasing Potential , Recharging Capacity, Permanent Teeth.

*Lecturer of Dental Biomaterials, Department of Dental Biomaterials, Faculty of Dentistry, Tanta University, Tanta, Egypt ** Assistant Professor of Operative Dentistry, Department of Conservative Dentistry, Zagazig University, Zagazig, Egypt. 


\section{INTRODUCTION}

Over the last 30 years, dentistry has experienced a remarkable scientific advance regarding the improvement of restorative materials and techniques. Many different restorative materials were introduced to provide the best intraoral performance in terms of durability, aesthetics and symptom relief ${ }^{(1)}$.

The addition of fluoride to restorative materials has attracted the attention of dental researchers and clinicians due to the possibility of their use as a reservoir releasing small amounts of fluoride, especially in patients with high caries risk ${ }^{(2)}$. The story of the recognition and exploration of fluoride's ability to prevent caries occurrence or progression is long and interesting ${ }^{(3)}$.

Fluoride has been known to have a role in the reduction of dental caries since early observations in the $1930 \mathrm{~s}{ }^{(4)}$. It increases the tooth resistance to caries through different protective mechanisms such as biological and physicochemical. Biologically, fluoride can interfere with pellicle and plaque formation. It also affects the metabolic activity of cariogenic bacteria and prevents it from secreting enzymes that ferment carbohydrates and subsequently decrease acid production. Moreover, fluoride plays a role in inhibition of microbial growth $^{(5)}$.

In addition, fluoride reverses the demineralization process in the oral cavity and enhances the remineralization by replacing the hydroxyl groups in the upper layers of the hydroxyapatite crystals to be fluoroappetite which results in a hard dental tissues with less solubility ${ }^{(6)}$.

Glass ionomers were invented by Wilson and Kent in the United Kingdom in 1969 as a restorative material, then developed by Mclean and Wilson and released commercially in the 1970s. This type of restoration has several advantages such as tooth color replication, biocompatibility, continuous fluoride ion release and uptake by enamel and dentin over a long period, coefficient of thermal expansion similar to that of tooth structure, inhibition of bacterial acid metabolism and activity, chemical bonding to both enamel and dentin, and ease of clinical application $^{(7)}$.

However, dentists did not widely accept these materials as a permanent restoration due to its susceptibility to dissolution during hardening, poor wear resistance and low fracture strengths, long setting times and unsatisfactory esthetics ${ }^{(8)}$.

Hybrid materials combining the technologies of glass-ionomer and composites were developed to overcome the previous disadvantages of glass ionomer cements. These hybrid materials mainly include Resin-modified glass ionomer cements (RMGIC's), compomers (polyacid-modified composites), Giomers and recently bioactive resin composites ${ }^{(6)}$. These hybrid materials were introduced to overcome the problem associated with conventional glass ionomers and composite resins and maintain their clinical advantages ${ }^{(9)}$. These materials have different setting mechanisms between acid-base reaction and free radical polymerization. ${ }^{(10)}$.

Resin modified glass ionomer cements (RMGIC's), are hybrid materials that retain a significant acid-base reaction as part of their overall curing process. In contrast, Compomers (polyacid modified composites) are hybrid aesthetic restorative materials that contains the glass ionomer fillers within the composite resin matrix. They became clinically favorable due to their improved physical and mechanical properties compared to glass ionomer restorative materials in addition to their ability to act as a reservoir for direct fluoride release to susceptible tooth surfaces in high caries risk $^{(11)}$.

On the other hand, Giomer (Beautifil II) is a new category of hybrid aesthetic restorative materials. It contains surface prereacted glass (S-PRG) ionomer filler particles which provide the properties of 
fluoride release of glass ionomer in addition to the superior physical properties of resin composite as claimed by manufacturer ${ }^{(13)}$.

A recent approach in restorative dentistry has been the introduction of a new type of bioactive restoratives (ACTIVA-Restorative, Pulpdent, Watertown, MA, USA) was launched globally in $2013^{(14,15)}$ which are lately introduced enhanced RMGIs. Their manufacturer claims to possess the general properties of a RMGI with a modified bioactive ionic resin matrix with enhanced resilience and physical properties, having both light polymerization ability and chemical cure. Thus, there are three hardening mechanisms involved with the ACTIVA product. According to the manufacturer, this restorative material is the first bioactive dental material with an ionic resin matrix and bioactive fillers that mimic the physical and chemical properties of natural teeth. They also claimed that ACTIVA has more fluoride ions release than glass ionomers. Thus, an enhanced RMGI was an interest to be evaluated with respect to its fluoride release and recharge properties ${ }^{(14,16)}$.

In view of the development of newer materials in the market, clinicians often have uncertainties regarding the choice of best materials to achieve optimum results. A comparative evaluation of available fluoride releasing restorative materials would help the clinician to select better products. Thus, the aim beyond this study was to asses and compare the fluoride releasing potential and recharging capacity of different bioactive restorative materials in-vitro

The first null hypothesis was that GICs, RMGI, compomers, giomers and ACTIVA- Bioactive Restorative would have the same fluoride releasing potential. The second null hypothesis was that there would be no difference in the fluoride recharging capacity between the tested restorative materials after exposure to topical fluoride varnish.

\section{MATERIALS AND METHODS}

\section{Materials}

Five different commercially available fluoride releasing restorative materials were investigated in the present study. The evaluated materials and their characteristics according to the data provided by the manufacturers; were presented in Table (1). All materials were manipulated according to the manufacturer's recommended directions.

- 5\% Sodium Fluoride Varnish (Duraphate, Colgate-Palmolive Arabia L.T.D. K.S.A) was used as topical fluoride varnish.

\section{Methods}

\section{Teeth collection and specimens preparation:}

Fifty sound non-carious freshly extracted human upper and lower premolar teeth were used. The selected teeth were extracted due to orthodontic purpose (patient aged from 12 to 16 years old); were collected from the clinic of maxillofacial surgery, Faculty of Dentistry, Tanta University. The purpose of the present study was explained to the patient and informed consents were obtained to use their extracted teeth on the research according to the guidelines on human research published by the Research Ethics Committee at Faculty of Dentistry, Tanta University.

All teeth were cleaned of debris and stored in aqueous thymol solution ( $0.1 \% \mathrm{wt} . / \mathrm{vol}$.) to prevent bacterial and fungal growth. All calculus and soft deposits were removed from the teeth with hand scaler (Scaler 10A, NOVA instruments Ltd, BerkShire, UK). The teeth were cleaned using a fluoride free pumice and low speed handpiece then they were rinsed with distilled water. After that, they were dried thoroughly using oil and moisture-free air source. Then, the teeth were carefully examined using magnifying glass and any tooth with visible cracks, hypoplasia, white spot lesion, or caries on any 
surface were excluded from the study ${ }^{(17)}$. The teeth were incubated at $37^{\circ} \mathrm{C}$ in artificial saliva $[500 \mathrm{ml}$ distilled water, $1.2 \mathrm{~g}$ Potassium Chloride, $0.843 \mathrm{~g}$ Sodium Chloride, 0.051g Magnesium Chloride, 20 $\mathrm{ml}$ stock solution of Tri-Calcium Phosphate (TCP) $1 \%(10.5 \mathrm{~g}$ TCP and $200 \mathrm{ml}$ of $1.0 \mathrm{M}$ hydrochloric acid) and Carboxy-methylcellulose. Sodium Hydroxide $(0.05 \mathrm{M})$ was added to the mixture to have a $\mathrm{pH}$ of 7$]^{(18)}$.

Standardized non-beveled class V cavities were prepared on the buccal surfaces of premolar teeth in the cervical $1 / 3$ of each tooth. To standardize cavity preparation of all teeth; a class $\mathrm{V}$ cavity was prepared in a tofflemire matrix band with dimensions ( $3 \mathrm{~mm}$ mesiodistally $\mathrm{x} 2 \mathrm{~mm}$ ooclusocervically) then the band was adapted on all teeth during preparation using tofflemiere retainer. Fifty cavities were made using carbid fissure bur (Komet H21314008 Lot 980042 Lemgo, Germanay) mounted at a high speed with air/water cooled hand piece. Class V cavities were designed as followed $(3 \mathrm{~mm}$ mesiodistally x $2 \mathrm{~mm}$ ooclusocervically x $2 \mathrm{~mm}$ (depth) pulpally). A standardized cavity depth of $2 \mathrm{~mm}$ was achieved using half the length of the cutting tip of the carbid fissure bur, the occlusal margins of the cavities were in enamel, and the gingival margins located $1 \mathrm{~mm}$ above the cemento-enamel junction. The Bur was changed every five cavities, the cavities dimensions were checked using graduated periodontal probe . All prepared teeth were thoroughly cleaned with water and gently dried then restored with the selected restorative materials ${ }^{(19)}$.

\section{Grouping of the specimens}

Teeth were randomly divided into 5 main equal experimental groups ( $n=10$ / each group) according to restorative material used: Group I: was restored with conventional glass ionomer cement (CGIC's)

TABLE (1) The fluoride release materials investigated in this study and their composition

\begin{tabular}{|l|l|l|l|}
\hline Brand & Manufacturer & Type & Composition \\
\hline GC Fuji IX GP & $\begin{array}{l}\text { GC, } \\
\text { Tokyo, Japan }\end{array}$ & CGIC & $\begin{array}{l}\text { Powder: 95 \% strontium fluoroalumino-silicate } \\
\text { glass, 5\% polyacrylic acid } \\
\text { Liquid: 40\% aqueous polyacrylic acid }\end{array}$ \\
\hline GC Fuji II LC & $\begin{array}{l}\text { GC, } \\
\text { Tokyo, Japan }\end{array}$ & RMGIC & $\begin{array}{l}\text { 2-hydroxyethyl methacrylate, Polyacrylic acid and } \\
\text { water. 58 wt\% Fluoro-aluminumsilicate }\end{array}$ \\
\hline Dyract XP & $\begin{array}{l}\text { Dentsply, Konstanz, } \\
\text { Germany }\end{array}$ & Compomer & $\begin{array}{l}\text { UDMA, TCB resin, TEGDMA, } \\
\text { trimethacrylate resin. } \\
73 \text { wt\% Strontiumalumino- sodium-fluoro-phosphor- } \\
\text { silicate }\end{array}$ \\
\hline Beautifil-II & Shofu, kyoto, japan & Giomer & $\begin{array}{l}\text { Bis-GMA, UDMA, Bis-MPEP, TEGDMA. } \\
83.3 \text { wt\% Fluoro-silicate glass }\end{array}$ \\
\hline $\begin{array}{l}\text { ACTIVA- Bioactive } \\
\text { Restorative }\end{array}$ & $\begin{array}{l}\text { Pulpdent, } \\
\text { Watertown, } \\
\text { MA, USA }\end{array}$ & $\begin{array}{l}\text { Enhanced } \\
\text { RMGIC }\end{array}$ & $\begin{array}{l}\text { Blend of diurethane and other methacrylates } \\
\text { with modified polyacrylic acid. 55.4 wt\% Bioactive } \\
\text { glass and sodium fluoride }\end{array}$ \\
\hline
\end{tabular}

RMGIC: resin modified glass-ionomer cement; Bis-GMA: bisphenol-A-diglycidyl-methacrylate; TEGDMA: triethyleneglycol dimethacrylate; UDMA: urethane dimethacrylate; Bis-MPEPP: Bisphenol A polyethoxy Methacrylate; TCB: Carboxylic acid modified di-methacrylate; wt\%: weight percentage. 
(GC Fuji IX, GC Co, Tokyo, Japan) Group II: was restored with Resin-modified glass ionomer cement (RMGIC's) (Fuji II LC, GC Co, Tokyo, Japan). Group III: was restored with compomer (Dyract XP, DENTSPLY, DeTrey,Konstanz, Germany). Group IV: was restored with giomer (Beautifil II, Shofu, Kyoto, Japan). Group V was restored with an enhanced RMGIC (ACTIVA Bioactive-Restorative , Pulpdent Corporation, Oakland Street, Watertown, MA, USA). Pure Deionized (DI) water $(0.05 \mu \mathrm{S} /$ $\mathrm{cm}$ at $25^{\circ} \mathrm{C}$; Hydrolab, Dziewięć Włók, Poland) was used as control. All steps were done following the manufacturer's instructions as follow :

\section{-Group I (GC F uji IX GP : CGIC)}

The cavities were washed with water and gently dried with air, avoiding over-drying. The ratio of the mixture should be 4.5 unit of powder (1 spoonful) to 1 unit of liquid (1 drop). A metal or plastic spatula should be used for the mixing process. The powder was divided into two parts and mixed with the liquid to create a homogenous structure. The material should not be mixed for more than $30 \mathrm{~s}$. The homogenous mixture was applied to the cavity in layers. The working time together with the mixing was 2 min and the setting time was 4-5 min. During the hardening process, the material is sensitive to moisture and should be insulated with varnish. ${ }^{(3)}$

\section{Group II (F uji II LC: RMGIC's)}

Cavity conditioner (GC Dentin conditioner, GC Corporation, Tokyo, Japan) was applied using a minibrush to rub the internal walls of the cavity then air dried for 10 seconds. The cavities were washed with water and gently dried with a cotton wool pellet and air. The prepared surfaces should appear damp. To prepare the RMGIC (Fuji II, GC Co, Tokyo, Japan) capsule for use, it was first shaken and the button was completely pushed as far as the capsule body. The capsule was quickly placed into a capsule gun and by pressing the trigger once, the mixture was made ready for use. The capsule was immediately placed into an amalgamator (Linea Tac Mixer, ex Kent Express, UK) and mixed at high speed $( \pm 4000$ $\mathrm{rpm}$ ) for $10 \mathrm{~s}$. The capsule was then inserted into the applicator gun and was injected into the cavity. The working time from the start of the mixing procedure was $1.5 \mathrm{~min}$. Greatest care was taken against moisture contamination throughout the first 2 min $30 \mathrm{~s}$. The starting contour was shaped. The polymerization period was $6 \mathrm{~min}$, after which the restoration was finished with standard techniques ${ }^{(12)}$.

\section{Group III (Dyract XP : Compomer)}

$37 \%$ Orthophosphoric acid gel (GCP CarboLed Lamp, GCP Dental, Ridderkerk, Netherlands) was applied to the cavities for $30 \mathrm{~s}$ to the enamel and 15 $\mathrm{s}$ to the dentin. The cavities were washed with an air-water spray and then gently air dried for $10 \mathrm{~s}$. The bonding agent (Prime and Bond NT) (etch-andrinse 2 -steps adhesive, Dentsply DeTrey, $\mathrm{GmbH}$, Konstanz, Germany) was applied and spread in the cavity with light air and then light cured for $10 \mathrm{~s}$. The compule of the Dyract XP was applied into the cavity in layers of up to $2 \mathrm{~mm}$ thickness and each layer was light cured for $20 \mathrm{~s}$. Polymerization of the materials was done using a hand held LED light curing unit (P11060012A LED P5 Guilin, Guangxi, Medical instrument CO., China) with a light intensity of $1200 \mathrm{~mW} / \mathrm{cm} 2$. A portable radiometer (Curing Radiometer, emetron, Danbury, CT, USA) was equipped to monitor the power intensity of the light curing device throughout the study. ${ }^{(13)}$.

\section{Group IV (Beautifil II: Giomer)}

Cavities were etched, bonded using FL-Bond II Giomer self-etch (2 steps) adhesive system ( Shofu Inc, Kyoto, Japan) and Beautifil II ( Giomer ) was placed in the cavities and photopolymerized for $20 \mathrm{~s}$ according to the manufacturer's instructions ${ }^{(18)}$. 
Group V : (Activa Bioactive-Restorative :enhanced RMGIC)

Cavities were etched, bonded using Scotchbond single-component universal Adhesive, (3M ESPE, Seefeld, Germany), the cavities were restored with "Activa" restorative material according to manufacturer's instructions..$^{(14,15,16)}$

The finishing and polishing procedures were applied to all the restored teeth in all the experimental groups using aluminum oxide-coated disks (SofLex, 3M ESPE, St. Paul, MN, USA). Then, all restored teeth were stored in labeled a tightly sealed labeled polyethylene test tube containing $5 \mathrm{ml}$ of DI water. Fluorine ion concentration in the DI water was zero ppm. All the samples were kept in the incubator at $37^{\circ} \mathrm{C}$ for 24 hours ${ }^{(16)}$.

\section{Fluoride Releasing Potential}

After 24 hours, polyethylene test tube were thoroughly shaken, and the teeth were removed, washed with $1 \mathrm{ml}$ of distilled water and re-immersed into a new vial containing $5 \mathrm{ml}$ of fresh DI water that was replaced every $24 \mathrm{~h}$. The previous procedure was repeated for each specimen for 28 days. Fluoride ion concentration (part per million : ppm) in the DI water was measured on 1st, 3th,7th, 14th , 21 th and 28 th days respectively ${ }^{(17,20,21)}$.

\section{Fluoride recharging capacity}

After measurement of fluoride releasing potential at the 28th day, each one of the specimen was carefully rinsed with distilled water, teeth subjected to recharging were taken from their test tubes and placed into a block of silicone impression material (Zetaplus, Italy) with premade "sockets" for their roots, This allow only the crowns and the restored cavities to be exposed during recharging with fluoride varnish. the base and catalyst of impression material was mixed and inserted into the block then the teeth inserted into the impression material before complete setting to make sockets for their roots)
(9). Then the restored teeth recharged with fluoride by application of 5\% Sodium Fluoride varnish (Duraphate, Colgate) on the buccal surface of all restored teeth using a disposable brush and allowed to dry for 5 minutes according to the manufacturer's instructions ${ }^{(21)}$.

Each recharged specimen was stored in $5 \mathrm{ml}$ of fresh DI water with zero ppm fluoride ion concentration in tightly sealed polyethylene test tubes and was incubated at $37^{\circ} \mathrm{c}$ for 24 hours. Each specimen was removed again to a new polyethylene test tube that contained $5 \mathrm{ml}$ of DI water which was replaced every $24 \mathrm{~h}$. The previous procedure was repeated for each specimen for another 28 days. The fluoride recharging capacity after application of Duraphate varnish was measured at the same release days as before; on 1st, 3rd, 7th, 14th , 21th and 28 th days respectively ${ }^{(19,20,21)}$.

\section{Measurement of fluoride ions concentration (ppm): Ion Chromatograph}

Each collected DI water sample was buffered with equal volume of TISAB II (Total Ionic Strength Adjustment Buffer solution, Hydromet S.C. , Gliwice, Poland) (2:2 mL; 1:1 ratio) which was then incubated at $37^{\circ} \mathrm{C}$. The TISAB II was used to control $\mathrm{pH}$ and prevent formation of fluoride complexes as it partially decomposes fluoride from polyvalent cations, consequently, making fluoride available for measurement ${ }^{(21)}$. Measurement of fluoride ion was done using Ion Chromatograph (ICS 3000, Dionex). Ion chromatograph was used to measure small quantities of free fluoride ions released from materials as this device can detect very low concentrations (above $0.001 \mathrm{ppm}$ ) of fluoride ions ${ }^{(19)}$.

Every 10 measurements, recalibrations were performed using multiple standard solutions of $0.1,1,10,50$ and $100 \mathrm{ppm}$ fluoride related to the concentration range to be studied (22). During the read-outs, the specimens were removed from the 
vials, rinsed with fresh DI water, dried with absorbent paper, and transferred to new DI water solutions. The solution was gently stirred during the analysis in a non heated magnetic stirrer. Measurements were taken from each sample at each time point and the average of the three measurements was used for the analysis. Before and after each measurement, the tip of the electrode was washed in distilled water and lightly dried to remove any remaining fluoride ions. Measurement of fluoride ions concentration (ppm) was done before and after recharging with Duraphate varnish at 1, 3, 7, 14, 21, 28 days. , the concentration of fluoride ions was averaged and expressed as mean \pm SD in ppm ${ }^{(23)}$.

\section{Statistical analysis}

Calculation of the mean and standard deviation (SD) values were done for each group. ShapiroWilk tests were used to explore data for normality. Parametric (normal) distribution was shown. To compare between two groups the independent sample-t test was used. Repeated measure ANOVA test was employed to compare between more than two groups. The significance level was set at $\mathrm{P} \leq 0.05$. Statistical analysis was completed using IBM ${ }^{\circledR}$ SPSS ${ }^{\circledR}$ Statistics Version 20 for Windows.

\section{RESULTS}

Three-way ANOVA analysis for the effect of different tested variables on fluoride release was shown in Table 2. The results revealed that fluoride recharging capacity had a statistical significant effect on mean fluoride releasing potential at F-value 5369.32 and $\mathrm{P}$-value $<0.001$. Material type had statistically significant effect at F-value 158.698 and $\mathrm{P}$-value $<0.001$. Time interval had statistically significant effect at F-value 491.254 and $\mathrm{P}$-value $<0.001$. The interaction between the three variables had a statistically significant effect on fluoride release. Mean and standard deviation (SD) values of fluoride release before recharging of the tested materials at different tested periods were shown in Table 3. For each tested material; there was a statistically significant difference between different tested times at (1st, 3rd, 7th, 14th, 21 th and 28 th days) where $(\mathrm{p} \leq 0.001)$. The highest mean value of fluoride release was in (Day 1), $(15.37 \pm 0.28$, $12.72 \pm 0.47,8.21 \pm 0.44,14.87 \pm 0.5$ and13.97 \pm 0.09$)$ for CGIC (GC Fuji IX GP), RMGI (Fuji II LC), Compomer (Dyract XP), Giomer (Beautifill II)and enhanced RMGI (ACTIVIA Bioactive-Restorative) respectively. The least mean value of fluoride release was in (Day 28), $(10.52 \pm 0.46,8.1 \pm 0.05$, $7.00 \pm 0.66,9.54 \pm 0.86$ and $9.44 \pm 0.19)$ for CGIC (GC Fuji IX GP), RMGI (Fuji II LC), compomer (Dyract $\mathrm{XP}$ ), giomer (Beautifill II) and enhanced RMGI (ACTIVIA Bioactive-Restorative) respectively.

Regarding comparing the five tested materials at each time interval; results revealed a statistically significant difference between the tested materials at each time interval (1st, 3rd, 7th, 14th, 21th and 28th days) where ( $\mathrm{p} \leq 0.001)$. CGIC (GC Fuji IX GP) showed the highest fluoride release mean values before recharge while the lowest value was observed in compomer (Dyract XP)at each time interval $\left(1^{\text {st }}, 3^{\text {rd }}, 7^{\text {th }}, 14^{\text {th }}, 21^{\text {th }}\right.$ and $28^{\text {th }}$ days $)$ at p-values $(0.005,0.015,0.019,0.017,0.009$, and $0.008)$ respectively.

Mean and SD values of fluoride release after recharge of different groups were shown in Table 3. For each tested material; there was a statistically significant difference between different tested times (1st, 3rd, 7th, 14th, 21th and 28th days) where $(\mathrm{p} \leq 0.001)$. The highest mean value of fluoride release after recharge was in (Day 1), $(15.37 \pm 0.28$, $12.72 \pm 0.47,8.21 \pm 0.44,14.87 \pm 0.5$ and13.97 \pm 0.09$)$ for CGIC (GC Fuji IX GP), RMGI (Fuji II LC), compomer (Dyract XP), giomer (Beautifill II)and enhanced RMGI (ACTIVIA Bioactive-Restorative) respectively and the least mean value of fluoride release after recharge was in (Day 28), (10.52 \pm 0.46 , $8.1 \pm 0.05,7.00 \pm 0.66,9.54 \pm 0.86$ and $9.44 \pm 0.19)$ for CGIC (GC Fuji IX GP), RMGI (Fuji II LC), compomer (Dyract XP), giomer (Beautifil II)and 
enhanced RMGI (ACTIVIA Bioactive-Restorative) respectively

The highest mean value of fluoride recharging capacity was in (Day 1$),(15.37 \pm 0.28,12.72 \pm 0.47$, $8.21 \pm 0.44,14.87 \pm 0.5$ and13.97 \pm 0.09$)$ for CGIC (GC Fuji IX GP), RMGI (Fuji II LC), compomer (Dyract XP), giomer (Beautifil II) and enhanced RMGI (ACTIVIA Bioactive-Restorative) respectively and the least mean value of fluoride recharging capacity was in (Day 28), ( 0.91 \pm 0.02 , $0.24 \pm 0.01,0.14 \pm 0.009,0.39 \pm 0.007$ and $0.22 \pm 0.009)$ for CGIC (GC Fuji IX GP), RMGI (Fuji II LC), compomer (Dyract XP), giomer (Beautifil II) and enhanced RMGI (ACTIVIA Bioactive-Restorative) respectively. In addition; there was a statistically significant difference between the mean value of fluoride recharging capacity between the tested materials at each tested time interval. Where CGIC (GC Fuji IX GP) showed higher fluoride release mean values after recharge while the lowest value was observed in compomer (Dyract XP) at each time interval $\left(1^{\text {st }}, 3^{\text {rd }}, 7^{\text {th }}, 14^{\text {th }}, 21^{\text {th }}\right.$ and $28^{\text {th }}$ days $)$ at p-values $(0.006,0.009,0.003,0.001,0.001,0.003$, and $\leq 0.001)$ respectively.

The highest mean value of fluoride recharging capacity was in (Day 1$),(15.37 \pm 0.28,12.72 \pm 0.47$,

TABLE (2): Three-way ANOVA for the effect of different variables on fluoride release

\begin{tabular}{|l|c|c|c|c|c|}
\hline Source of variation & $\begin{array}{c}\text { Type III } \\
\text { Sum of Square }\end{array}$ & df & Mean Square & F-value & P-value \\
\hline Before and After recharge & 7246.393 & 1 & 7246.393 & 5369.32 & $\leq 0.001 *$ \\
Material type & 1050.634 & 4 & 1050.634 & 158.698 & $\leq 0.001^{*}$ \\
Time interval & 1500.265 & 1 & 150.888 & 491.254 & $\leq 0.001^{*}$ \\
Before and after recharge x & 267.298 & 5 & 13.0563 & 36.349 & $\leq 0.001 *$ \\
Material type x & & & & & \\
$\quad$ Time interval interaction & & & & & \\
\hline
\end{tabular}

df: degrees of freedom $=(n-1)$, Significant at $P \leq 0.05$.

TABLE (3) : The mean, standard deviation (SD) values of Fluoride release (ppm) before recharge of different groups.

\begin{tabular}{|c|c|c|c|c|c|c|}
\hline \multirow[b]{2}{*}{ Variables } & \multicolumn{5}{|c|}{ Fluoride release before recharge } & \multirow[b]{2}{*}{ P-value } \\
\hline & $\begin{array}{c}\text { CGIC } \\
(\text { GC Fuji IX GP) } \\
\text { Mean } \pm \text { SD } \\
\end{array}$ & $\begin{array}{c}\text { RMGI } \\
(\text { Fuji II LC) } \\
\text { Mean } \pm \text { SD }\end{array}$ & $\begin{array}{c}\text { Compomer } \\
(\text { Dyract XP) } \\
\text { Mean } \pm \text { SD }\end{array}$ & $\begin{array}{c}\text { Giomer } \\
\text { (Beautifill II) } \\
\text { Mean } \pm \text { SD }\end{array}$ & $\begin{array}{c}\text { Enhanced RMGI } \\
\text { (ACTIVA- Bioactive } \\
\text { Restorative) Mean } \pm \text { SD }\end{array}$ & \\
\hline Day 1 & $21.05 \pm 2.14$ & $17.36 \pm 0.71$ & $13.54 \pm 0.47$ & $19.81 \pm 0.82$ & $18.61 \pm 1.09$ & $0.005 *$ \\
\hline Day 3 & $18.17 \pm 0.28$ & $15.81 \pm 0.47$ & $12.01 \pm 0.18$ & $17.01 \pm 0.81$ & $16.97 \pm 0.95$ & $0.015 *$ \\
\hline Day 7 & $16.52 \pm 0.69$ & $13.9 \pm 0.55$ & $10.82 \pm 0.23$ & $15.03 \pm 0.7$ & $15.02 \pm 0.87$ & $0.019 *$ \\
\hline Day 14 & $15.81 \pm 0.47$ & $12.17 \pm 0.99$ & $9.1 \pm 0.71$ & $13.99 \pm 0.01$ & $13.01 \pm 0.01$ & $0.017 *$ \\
\hline Day 21 & $13.16 \pm 1.11$ & $10.83 \pm 0.66$ & $8.11 \pm 0.87$ & $11.8 \pm 0.79$ & $11.02 \pm 0.05$ & $0.009 *$ \\
\hline Day 28 & $10.52 \pm 0.46$ & $8.1 \pm 0.05$ & $7.00 \pm 0.66$ & $9.54 \pm 0.86$ & $9.44 \pm 0.19$ & $0.008 *$ \\
\hline P-value & $\leq 0.001 *$ & $\leq 0.001 *$ & $\leq 0.001 *$ & $\leq 0.001 *$ & $\leq 0.001 *$ & \\
\hline
\end{tabular}

*; significant $(p<0.05)$ 
TABLE (4) : The mean, standard deviation (SD) values of Fluoride release (ppm) after recharge of different groups.

\begin{tabular}{|c|c|c|c|c|c|c|}
\hline \multirow[b]{2}{*}{ Variables } & \multicolumn{5}{|c|}{ Fluoride release before recharge } & \multirow[b]{2}{*}{ P-value } \\
\hline & $\begin{array}{c}\text { CGIC } \\
(\text { GC Fuji IX GP) } \\
\text { Mean } \pm \text { SD }\end{array}$ & $\begin{array}{c}\text { RMGI } \\
(\text { Fuji II LC) } \\
\text { Mean } \pm \text { SD }\end{array}$ & $\begin{array}{l}\text { Compomer } \\
(\text { Dyract XP) } \\
\text { Mean } \pm \text { SD }\end{array}$ & $\begin{array}{c}\text { Giomer } \\
\text { (Beautifill II) } \\
\text { Mean } \pm \text { SD }\end{array}$ & $\begin{array}{c}\text { Enhanced RMGI } \\
\text { (ACTIVA- Bioactive } \\
\text { Restorative) } \\
\text { Mean } \pm \text { SD }\end{array}$ & \\
\hline Day 1 & $15.37 \pm 0.28$ & $12.72 \pm 0.47$ & $8.21 \pm 0.44$ & $14.87 \pm 0.5$ & $13.97 \pm 0.09$ & $0.006 *$ \\
\hline Day 3 & $7.27 \pm 0.57$ & $4.19 \pm 0.68$ & $0.98 \pm 0.28$ & $2.19 \pm 0.08$ & $0.99 \pm 0.02$ & $0.009 *$ \\
\hline Day 7 & $6.91 \pm 0.55$ & $2.09 \pm 0.59$ & $0.35 \pm 0.01$ & $0.64 \pm 0.019$ & $0.59 \pm 0.03$ & $0.003 *$ \\
\hline Day 14 & $1.95 \pm 0.09$ & $1.98 \pm 0.03$ & $0.25 \pm 0.02$ & $0.59 \pm 0.001$ & $0.49 \pm 0.008$ & $0.001 *$ \\
\hline Day 21 & $1.01 \pm 0.07$ & $0.29 \pm 0.01$ & $0.19 \pm 0.01$ & $0.46 \pm 0.002$ & $0.34 \pm 0.01$ & $0.001 *$ \\
\hline Day 28 & $0.91 \pm 0.02$ & $0.24 \pm 0.01$ & $0.14 \pm 0.009$ & $0.39 \pm 0.007$ & $0.22 \pm 0.009$ & $\leq 0.001 *$ \\
\hline P-value & $\leq 0.001 *$ & $\leq 0.001 *$ & $\leq 0.001 *$ & $\leq 0.001 *$ & $\leq 0.001 *$ & \\
\hline
\end{tabular}

*; significant $(p<0.05)$

\section{$8.21 \pm 0.44,14.87 \pm 0.5$ and13.97 \pm 0.09$)$ for CGIC}

(GC Fuji IX GP), RMGI (Fuji II LC), Compomer (Dyract XP), Giomer (Beautifill II) and enhanced RMGI (ACTIVIA Bioactive-restorative) respectively and the least mean value of fluoride recharging capacity was in (Day 28), (0.91 \pm 0.02 , $0.24 \pm 0.01,0.14 \pm 0.009,0.39 \pm 0.007$ and $0.22 \pm 0.009)$ for CGIC (GC Fuji IX GP), RMGI (Fuji II LC), Compomer (Dyract XP), Giomer (Beautifil II) and enhanced RMGI (ACTIVIA Bioactive-restorative) respectively. In addition; there was a statistically significant difference between the mean value of fluoride recharging capacity between the tested materials at each tested time interval. Where CGIC (GC Fuji IX GP) showed higher fluoride release mean values after recharge while the lowest value was observed in Compomer (Dyract XP) at each time interval $(1,3,7,14,21,28$ days $)$ at $\mathrm{p}$-values $(0.006,0.009,0.003,0.001,0.001,0.003$, and $\leq 0.001)$ respectively.

\section{DISCUSSION}

The currently increasing aesthetic demands of dental patients have played a significant role in the development of materials used for restorative purposes. GICs are widely used in dentistry because they possess a variety of suitable properties ${ }^{(7)}$. Chemical diffusion-base adhesion to enamel and dentin tissues and fluoride release are some of their important properties. Over time, several modifications have been made to glass ionomer material formulations which have led to improved materials and, consequently, clinical benefits. The latest innovations are glass ionomer materials that are based on the nanotechnology or contain the addition of fluoroapatite/ hydroxyapatite $^{(11)}$. Before these materials can be tested in clinical studies, it is essential to evaluate the performance of these newly produced glass ionomers in the laboratory. Therefore, the primary objective of this study was to asses and compare the fluoride releasing potential and recharging capacity of different bioactive restorative materials in-vitro. 
Five different commercially available fluoride releasing restorative materials were evaluated in this study namely : Conventional glass ionomer cement (CGIC's); G C Fuji IX G P, resin modified glass ionomer restoration (RMGI); Fuji II LC, compomer; Dyract XP, giomer; Beautifil II and one enhanced RMGI; ACTIVA Bioactive Restorative. The tested materials were known to have different clinical indications and comparison of properties in relation to the materials clinical use may not be justified. A large variation in the loading and constitution of filler particles could be seen in the different commercial materials tested.

One of the positive characteristics of GICs-based materials which makes them preferable as restorative materials is the capacity to release fluoride ${ }^{(24)}$. Fluoride release of a material is important in respect of the anticariogenic property. Continuous fluoride release by GICs prevents the formation of secondary caries ${ }^{(25,26)}$. It is accepted that CGICs are effective in the prevention of caries because of the property of long-term fluoride release. High fluoride release in the first $24 \mathrm{~h}$ reacting with polyalchenoic acid of glass particles during the polymerization reaction results in a "burst effect." The high fluoride release initially seen rapidly decreases after 24-72 h, approaches a stable level within 10-20 days, and the fluoride in the cement content is used up extremely quickly within a few months ${ }^{(27,28)}$.

Fluoride release from a GIC is a complex process and affected by intrinsic and extrinsic factors. Intrinsic factors include formulation, powder/ liquid ratio, specimen geometry, temperature, mixing time, solubility or porosity of the material, surface treatment, and finishing. ${ }^{[13-17]}$ Extrinsic factors include type and $\mathrm{pH}$ of storage medium, experimental design, the environmental temperature, and analytical methods. In this study, specimen geometry, surface treatment, environmental temperature, the type and $\mathrm{pH}$ of the storage medium, the experimental design, analytic method, and finishing were standardized for all materials. ${ }^{(13,17)}$.
The drop in fluoride release over time reduces the ability of the material to prevent the formation of secondary caries, because fluoride released at low doses is not sufficient for a protective effect against caries ${ }^{(3)}$. However, CGIC has the capacity to be able to take fluoride from the surroundings depending on the concentration gradient. Therefore, these cements are accepted as a fluoride depot ${ }^{(4)}$.

Duraphate varnish was chosen in the current study as topical fluoride varnish which is a common caries preventive measure used in pediatric dentistry ${ }^{(29)}$. It was used to recharge the tested restorative materials in a way similar to the clinical situation. The ability of the topical fluoride agent for recharging a material is dependent on the dose, frequency, concentration and duration of application of this agent ${ }^{(30)}$. The fluoride re-release that occurs immediately after recharge is induced by superficial effect of the topical fluoride while during the subsequent days release is attributed to its ability to diffuse through the materials' pores and stored to be re-released ${ }^{(31)}$.

Many methods have been employed to estimate the amount of fluoride release such as spectrophotometry, ion chromatography, fluoride ion-specific electrodes and capillary electrophoresis. Ion chromatograph was used in this study because it is simple, inexpensive and does not require the use of complex laboratory equipment. Moreover, it gives an accurate, precise and direct estimate of the free fluoride present in solution ${ }^{(18)}$.

Deionized (DI) water, saliva or $\mathrm{pH}$-cycling models are preferred mediums to evaluate the fluoride release from dental materials. (32,33) Although saliva or $\mathrm{pH}$-cycling models could better simulate the oral environment, deionized water was used in our study as a medium because it is easily obtainable and reflects well the fluoride release of the materials without the confounding influence of minerals or organic molecules which might be presented in saliva or $\mathrm{pH}$-cycling solutions ${ }^{(32,33)}$.

In addition, DI water is easily available and more fluoride is released in deionized water than 
in artificial saliva ${ }^{(33)}$. Dionysopoulos et al. in 2013 reported that the fluoride release pattern from restorative materials were similar in solutions simulating $\mathrm{pH}$-cycling and deionized water ${ }^{(32)}$.

In the present study, all the tested materials released measurable quantities of fluoride during the 28-day period prior to topical fluoride recharging. However, there were large variations in the amount of fluoride released from the tested materials. Fluoride release from GICs occurred by means of three mechanisms: Surface loss, diffusion through pores and cracks, and bulk diffusion ${ }^{(8)}$. All fluoride-releasing dental materials investigated in this study released the greatest amount of fluoride ions on the 1st-day. Fluoride continued to be released in relatively low amounts from day 3 until day 28. The high level of fluoride release from GIC materials on day 1 was probably due to an initial "burst" of fluoride release from the glass particles. The burst release is attributed to the reaction of the polyalkenoic acid with the fluoride-containing glass particles during the setting reaction and also to the rapid dissolution of fluoride from the outer surface into the solution ${ }^{(9)}$.

This was in agreement with a number of in -vitro studies that have also shown higher fluoride release in the first two days ${ }^{(9,10,13)}$. The slower release of fluoride during subsequent days has been attributed to the slower dissolution of glass particles through cement pores and fractures. Bulk fluoride diffusion occurs during the maturation period as a consequence of contact between the GIC material with the storage medium ${ }^{(20)}$.

Among the restorative materials, CGIC (GC Fuji IX GP) released significantly the highest amount of fluoride ion before and after recharging at each tested time. In general, a direct relationship exists between the amount of fluoride present in the cement and the amount of fluoride released ${ }^{(10,13)}$. In comparison to GC Fuji IX GP, which is conventional GICs, enhanced RMGI (ACTIVABioactive Restorative) released less fluoride.
To date, several studies have compared the fluoride release pattern of RMGICs and conventional high-viscosity GICs. The studies comparing conventional and the modified ionomers for fluoride release are controversial: ranging from similar, inferior to superior results for the modified cements ${ }^{(32)}$. Some researchers found that the fluoride releasing potential of RMGICs is equal to that of conventional GICs . However, several variables affect the fluoride releasing potential of RMGICs. These include the type and amount of resin used for photochemical polymerization reaction and the presence of fluoride compounds and their interaction with polyalkenoic $\operatorname{acids}^{(18,19)}$. Our results are consistent with the results of Dionysopoulos et al., in 2013 which indicated that RMGICs released less fluoride when compared with a conventional GIC ${ }^{(32)}$.

As Regards to compomer, our study agreed with Neelakantan et al in 2011 $1^{(34)}$ and Bansal and Bansal in $2017^{(30)}$, where their study showed that compomer had no initial fluoride "burst" effect but lower constant level of fluoride release than conventional GIC from the first day throughout the 28 days study period. On contrary, study of Mousavinasab et al in $2009^{(35)}$ showed that GICs released significantly less fluoride than compomer on the 1st week. In contrast, Al-Naimi et al showed in $2008{ }^{(36)}$ that Fluoride release of GICS, compomer and giomer in natural saliva with normal $\mathrm{pH}$ was comparable and no statistically significant difference existed between them. Moreover, Gui et al in 2015 (37) proved in their study that GICS, compomer and giomer released comparable amounts of fluoride.

Reductions in the rate of fluoride releasing and the recharging capacity of the fluoride-releasing materials became interesting and important issues, especially for patients with a high risk of caries. The fluoride recharging capacity of GICs tested in the present study agreed with the results of other studies ${ }^{(13,18)}$. All the tested materials were found to recharge with fluoride and re-release it again. After fluoride recharging, fluoride release increased in the first $24 \mathrm{~h}$, but after this period, the amount of 
fluoride re-release from all materials experienced a sharp drop ${ }^{(18,19)}$.

The precise mechanism of fluoride uptake by the restorative materials is not fully understood. Restorative materials to perform as a fluoride reservoir are largely dependent on the type and permeability of the material, plus their ability to retain fluoride ${ }^{(38)}$, temperature, and the contact area with the storage medium ${ }^{(39)}$. In addition, the rate and time of fluoride exposure and the type and concentration of the fluoridating agent had also great influence ${ }^{(40)}$.

Results obtained from the current study indicated the importance of topical fluoride application. The current study showed that all the tested materials could be recharged with Duraphate varnish. Conventional GICs exhibited significantly higher fluoride re-release than the other tested materials. This finding may be attributed to that GICs are significantly more porous and permeable than other investigated materials, thus enhancing fluoride release/ re-release ${ }^{(18)}$. These findings indicated that materials with higher initial fluoride release have higher recharging capacity, which is consistent with the results of other studies ${ }^{(19,20)}$.

In 2014 , according to Jingarwar ${ }^{(31)}$, the ability of a material to exhibit fluoride recharging depends on its ability to retain fluoride. The glass ionomer phase incorporated within the tested materials is responsible for their fluoride recharge. The relatively hydrophobic nature of the resin matrices of the materials implicates the glass ionomer as the key reason for the additional recharge. The hydrogel of PRG particles in giomer exhibits a high permeability and porosity which consequently provides giomer with areas within its structure capable of greater fluoride uptake ${ }^{(18,19)}$.

After the application of the Duraphate fluoride varnish for fluoride recharging; there was a statistically significant difference between the mean value of fluoride ion concentration, where the enhanced RMGI (ACTIVIA Bioactive-Restorative) showed a lower fluoride re-release value than CGIC (GC Fuji IX GP), a higher fluoride re-release value than both Compomers and RMGI and comparable to that of Giomer at all measured times .

ACTIVA Bioactive-Restorative, contain a patented, resilient resin matrix with energy-absorbing elastomeric components (a blend of diurethane and methacrylates with modified polyacrylic acid and polybutadiene modified diurethane dimethacrylate) ${ }^{(41)}$. This patented resin matrix might affect the permeability of this enhanced RMGI, leading to lower ability to be recharged and acting like fluoride reservoir. Also, results of our study revealed that the highest statistical significant mean values of fluoride re-release were at the first day after recharge, then declines rapidly for all tested materials. This indicates that only superficial part of the specimens has been recharged due to the short fluoride recharging time (5 $\mathrm{min})$ that was applied once to the specimens in this study ${ }^{(19)}$

Our results agreed with some of the previous findings. Rothwell et al in $1998^{(42)}$ examined fluoride release before and after the application of a toothpaste of CGIC, 2 RMGICs, and a compomer. According to the results of that study, the most fluoride release was observed in the RMGICs. Although the fluoride release of all the materials increased after the application of the toothpaste, it fell again to the initial level within 3 days. While, our results disagreed with Selimovic-Dragas et al. in $2013^{{ }^{(43)}}$ who compared the fluoride releasing potenial of CGIC and RMGICs and he showed that fluoride release of the RMGICs was reported to be higher than that of CGIC at all the measured times.

Dhull et al in $2011^{(13)}$. found that increasing fluoride exposure time significantly increased fluoride release from GIC. Also, in agreement with the results of this study, they found that giomer showed comparatively greater fluoride recharging capacity than compomer with a statistically significant difference. In contrast with the results of our study, Gururaj et al in $2013^{(19)}$ compared in -vitro the fluoride re-release from 5 different flouride releasing restorative materials. They concluded that 
recharging capability of compomer was the highest among the tested materials.

Choudhary et al in $2015^{(18)}$ and Harhash et al in $2017^{(44)}$ evaluated releasing potential of fluoride ions from GIC, compomer and giomer before and after recharging with topical fluoride gel. They found that significant decrease of fluoride release from day 1 to day 7 and fluoride release at day seven was significantly greater than at day 21 . Kucukyilmaz et al in $2017^{(22)}$ showed that high viscosity GICs show higher initial fluoride releasing potential as well as greater fluoride recharging capacity.

Garoushi et al. in $2018^{(45)}$ evaluated and compared certain properties, including fluoride releasing potential of four fluoride-releasing restorative materials (RMGIC, compomer, giomer, and ACTIVA-Restorative). At the end of their research, they reported that, the highest fluoride-release / re-release measurement was located for RMGIC among the other tested materials.

Malik et al. in $2018^{(46)}$ found out the amount of fluoride release/ re-release from GIC-containing fluoroapatite and hydroxyapatite. As a result of their study, it was concluded that addition of fluoroapatite into GIC had a significant effect on the amount of fluoride release / re-release as compared to GIC alone. However, addition of hydroxyapatite into GIC had no additive effect on the amount of fluoride release.

A possible limitation of the present study is that the dynamic nature of conditions found actually in the oral cavity such as salivary flow characteristics, presence of plaque, oral hygiene and dietary habits utilized by the patient which can lead to results that may be different from what have been proven in the current study. Thus further studies employing clinical trials are important.

Based on our results, the first and the second null hypothesis could be rejected since a statistically significant difference was found in the fluoride releasing potential and recharging capacity among the different tested materials at each time interval.

\section{CONCLUSION}

Within the limits of this in vitro study, it could be concluded that the CGIC was considered to be the material with the highest fluoride releasing potential and recharging capacity at each time interval, while compomer showed the lowest fluoride releasing potential and recharging capacity at each time interval. It was observed that the enhanced RMGI (ACTIVIA Bioactive-Restorative) showed a lower fluoride releasing potential and fluoride recharging capacity than those of CGIC (GC Fuji IX GP), a higher values than those of both Compomers and RMGI and comparable to those of giomer at each time interval. ACTIVA Bioactive-Restorative, could be considered a suitable class $\mathrm{V}$ restoration in high caries risk patients.

\section{REFERENCES}

1. Garcez RM, Buzalaf MA, De Araújo PA. Fluoride release of six restorative materials in water and ph-cycling solutions. J Appl Oral Sci 2007; 15:406-11.

2. Murray JJ, Rugg-Gunn AJ, Jenkins GN. Fluorides in caries prevention. J Dent 1993; 21:259-320.

3. John WN. Fluoride-Releasing Dental Restorative Materials: An Update. Balk J Dent Med 2014; 18:60-9.

4. American Academy of Pediatric Dentistry. Guideline on fluoride therapy. Pediatr Dent 2014; 35:165-8.

5. Hicks J, Garcia-Godoy F, Donly K, Flaitz K, Calif J. Fluoride-releasing restorative materials and secondary caries. J Calif Dent Assoc 2003; 31: 229-45.

6. Berg JH, Croll TP. Glass ionomer restorative cement systems: an update. Pediatr Dent. 2015; 37:116-24.

7. Najeeb S, Khurshid Z, Zafar MS, Khan AS, Zohaib $\mathrm{S}$, MartiJMN, et al. Modifications in glass ionomer cements:nano-sized fillers and bioactive nanoceramics. Int J Mol Sci 2016;17(7):1-14.

8. Tiwari S, Nandlal B. Effect of nano-filled surface coating agent on fluoride release from conventional glass ionomer cement: an in vitro trial. J Indian Soc Pedod Prev Dent 2013; 31; 91-5.

9. Mungara J, Philip J, Joseph E, Rajendran S, Elangovan A, Selvaraju G. Comparative evaluation of fluoride release and recharge of pre-reacted glass ionomer 
composite and nano-ionomeric glass ionomer with daily fluoride exposure: An in vitro study. J Indian Soc Pedod Prev Dent 2013; 31:234-9.

10. Walia R, Jasuja P, Verma KG, Juneja S, Mathur A, Ahuja L. A comparative evaluation of microleakage and compressive strength of Ketac Molar, Giomer, Zirconomer, and Ceram-x: An in vitro study. J Indian Soc Pedod Prev Dent 2016; 34:280-4.

11. Yap AU, Wang X, Wu X, Chung SM. Comparative hardness and modulus of tooth-colored restoratives: a depthsensing microindentation study. Biomaterials 2004; 25 : 2179-2185.

12. van Dijken JW, Pallesen U. Fracture frequency and longevity of fractured resin composite, polyacid-modified resin composite, and resin-modified glass ionomer cement class IV restorations: an up to 14 years of follow-up. Clin Oral Investig 2010; 14: 217-222.

13. Dhull KS, Nandlal B. Effect of low-concentration daily topical fluoride application on fluoride release of giomer and compomer: an in vitro study. J Indian Soc Pedod Prev Dent 2011; 29:39-45.

14. Croll TP, Berg JH, Donly KJ. Dental repair material: a resin modified glass-ionomer bioactive ionic resin-based composite. Compend Contin Educ Dent 2015; 36: 60-65.

15. Lassila L, Garoushi S, Vallittu PK, Säilynoja E. Mechanical properties of fiber reinforced restorative composite with two distinguished fiber length distribution. J Mech Behav Biomed Mater 2016; 60: 331-338.

16. Pameijer CH, Garcia-Godoy F, Morrow BR, Jefferies SR. Flexural strength and flexural fatigue properties of resinmodified glass ionomers. J Clin Dent 2015;26(1):23-7.

17. Guedes AP et al. Effect of Fluoride-Releasing Adhesive Systems on the Mechanical Properties of Eroded Dentin. Braz Dent J 2016; 27:153-9.

18. Choudhary HV, Tandon S, Rathore M, Gopal K, Tiwari N. Fluoride release and uptake by glass ionomer cements, Polyacid modified composite resin and giomer- an in vitro Assessment. IJOCR 2015; 3:68-74.

19. Gururaj M, Shetty R, Nayak M, Shetty S, Kumar CV. Fluoride releasing and uptake capacities of esthetic restorations. J Contemp Dent Pract 2013; 14:887-91.

20. Attar N, Önen A. Fluoride release and uptake characteristics of aesthetic restorative materials. J Oral Rehabl 2002;29(8):791-829.
21. Dionysopoulos P, Kotsanos N, Pataridou A. Fluoride release and uptake by four new fluoride releasing restorative materials. J Oral Rehabil 2003;30:866-72.

22. Kucukyilmaz E, Savas S, Kavrik F, Yasa B, Botsali MB. Fluoride release/recharging ability and bond strength of glass ionomer cements to sound and caries-affected dentin. Niger J Clin Pract 2017;20:226-34.

23. Sule B, Emine ST, Abdurrahman A, Ertan E, Dilek G, Sezin O. Fluoride release and recharge from different materials used as fissure sealant. Euro J Dent 2010;4:245-50.

24. Gao W, Smales RJ, Yip NK. Demineralisation and remineralisation of dentine caries, and the role of glassionomer cements. Int Dent J 2000;50:51-6.

25. Nicks MJ, Flaitz CM. Resin-modified glass-ionomer restorations and in vitro secondary caries formation in coronal enamel. Quintessence Int 2000;31:570-8.

26. Moshaverinia A, Chee WW, Brantley WA, Schricker SR.Surface properties and bond strength measurements of $\mathrm{N}$-vinylcaprolactam (NVC)-containing glass-ionomer cements. J Prosthet Dent 2011;105:185-93.

27. Moshaverinia A, Rohpour N, Billington RW, Darr JA, Rehman IU. Synthesis of N-vnylpyrrolidone modified acrylic acid copdymer in supercritical fluids and its application in dental glass-ionomer cements. J Mater Sci Mater Med 2008;19:2705-11.

28. Wiegand A, Buchalla W, Attin T. Review on fluoride-releasing restorative materials-fluoride release and uptake characteristics, antibacterial activity and influence on caries formation. Dent Mater 2007;23:343-62.

29. Weyant RJ et al. Topical fluoride for caries prevention: Executive summary of the updated clinical recommendations and supporting systematic review. JADA 2013; 144:1279-91.

30. Bansal R, Bansal T. A Comparative Evaluation of the Amount of Fluoride Release and Re-Release after Recharging from Aesthetic Restorative Materials: An in vitro Study. JCDR. 2017; 11:11-4.

31. Jingarwar MM, Pathak A, Bajwa NK, Sidhu HS. Quantitative Assessment of Fluoride Release and Recharge Ability of Different Restorative Materials in Different Media: An in Vitro Study. J Clin Diagn Res 2014; 8:31-4.

32. Dionysopoulos D, Koliniotou-Koumpia E, Helvatzoglou-Antoniades M, Kotsanos N. Fluoride release and recharge abilities of contemporary fluoride-containing restorative materials and dental adhesives. Dent Mater J 2013;32:296-304. 
33. Karantakis $\mathrm{P}$, Helvatjoglou-Antoniades $\mathrm{M}$, Theodoridou-Pahini S, Papadogiannis Y. Fluoride release from three glass ionomers, a compomer, and a composite resin in water, artificial saliva, and lactic acid. Oper Dent 2000;25:20-5.

34. Neelakantan P, John S, Anand S, Sureshbabu N, Subbarao C. Fluoride release from new glass-ionomer cement. Oper Dent 2011; 36:80-5.

35. Mousavinasab SM, Meyers I. Fluoride release by glass ionomer cements, compomer and giomer. Dent Res J (Isfahan) 2009; 6:75-81.

36. Al-Naimi OT1, Itota T, Hobson RS, McCabe JF. Fluoride release for restorative materials and its effect on biofilm formation in natural saliva. J Mater Sci Mater Med 2008; 19:1243-8.

37. Gui Y, Zhao X, Li S, Tang L, Gong X. Fluoride release and recharge properties of six restorative materials. Zhonghua Kou Qiang Yi Xue Za Zhi 2015; 50:28-32.

38. Temin SC, Csuros Z. Long-term fluoride release from a composite restorative. Dent Mater 1998;4:180-4

39. Verbeeck RMH, De Moor RJG, Van Even DFJ, Marens LC. The short-term fluoride release of a hand mixed vs. capsulated system of a restorative glass ionomer cement. J Dent Res 1993;72:577-81.
40. Dionysopoulos D. The effect of fluoride-releasing restorative materials on inhibition of secondary caries formation. Fluoride 2014;47(3):258-65.

41. Yap AUJ, Tham SY, Zhu LY, Lee HK. Short-term fluoride release from various aesthetic restorative materials. Operat Dent 2002;27:259-65.

42. Rothwell M, Anstice HM, Pearson GJ. The fluoride uptake and release of fluoride by ion-leaching cements after exposure to toothpaste. J Dent 1998;26:591-7.

43. Selimović-Dragaš M, Hasić-Branković L, Korać F, Đapo N, Huseinbegović A, Kobašlija S, et al. In vitro fluoride release from a different kind of conventional and resin modified glass-ionomer cements. Bosn J Basic Med Sci 2013;13:197-202.

44. Harhash AY, ElSayad II, Zaghloul AGS. A comparative in vitro study on fluoride release and water sorption of different flowable esthetic restorative materials. Eur J Dent 2017; 11:174-9.

45. Garoushi S, Vallittu PK, Lassila L. Characterization of fluoride releasing restorative dental materials. Dent Mater J 2018;37:293-300,

46. Malik S, Ahmed MA, Choudhry Z, Mughal N, Amin M, Lone MA. Fluoride release from glass ionomer cement containing fluoroapatite and hydroxyapatite. J Ayub Med Coll Abbottabad 2018;30:198-202. 